\title{
Tensile Regulation of Axonal Elongation and Initiation
}

\author{
Jing Zheng, Phillip Lamoureux, Vivian Santiago, Timothy Dennerll, ${ }^{a}$ Robert E. Buxbaum, and \\ Steven R. Heidemann
}

Department of Physiology, Michigan State University, East Lansing, Michigan 48824-1101

\begin{abstract}
Neurites of chick sensory neurons in culture were attached by their growth cones to glass needles of known compliance and were subjected to increasing tensions as steps of constant force; each step lasted 30-60 min and was 25-50 $\mu$ dyn greater than the previous step. After correcting for elastic stretching, neurite elongation rate increased in proportion to tension magnitude greater than a tension threshold. The value of the tension threshold required for growth varied between 25 and $560 \mu$ dyn, with most between 50 and $150 \mu$ dyn. The growth sensitivity of neurites to tension was surprisingly high: an increase in tension of $1 \mu$ dyn increased the elongation rate an average of about $1.5 \mu \mathrm{m} / \mathrm{hr}$. The linear relationship between growth rate and tension provides a simple control mechanism for axons to accommodate tissue expansion in growing animals that consistently maintains a moderate rest tension on axons. Styrene microspheres treated with polyethyleneimine were used to label the surface of neurites in order to determine the site and pattern of surface addition during the experimental "towed growth" regime. New membrane is added interstitially throughout the neurite, but different regions of neurite vary widely in the amount of new membrane added. This contrasts with membrane addition specifically at the distal end in growth-cone-mediated growth. The different sites for membrane addition in growth mediated by towing and by the growth cone indicate that the membrane addition process is sensitive to the mode of growth. We confirmed the finding of Bray (1984) that neurites can be initiated de novo by application of tension to the cell margin of chick sensory neurons. Initiation required tensions above some threshold and tension magnitudes very similar to those required for neurite elongation. Initiated neurites developed growth cones capable of normal motility and axonal elongation. Such neurites also contained a normal array of microtubules as assessed by immunofluorescence and by electron microscopy.
\end{abstract}

Evidence is accumulating that mechanical tension is an important regulator of axonal development (Heidemann and Buxbaum, 1990). Tension applied to neurites of chick sensory neu-

\footnotetext{
Received July 30, 1990; revised Nov. 12, 1990; accepted Nov. 19, 1990.

This work was supported by NSF Grant BNS 8807920 and NIH Grant GM 36894. We thank Dr. David Asai for his generous gifts of anti-tubulin antibody and for sharing his immunofluorescence protocol with us. We thank Dr. Paul Forscher for sharing his method for treating polystyrene microspheres.

Correspondence should be addressed to Steven $R$. Heidemann at the above address.

a Present address: Department of Medicine, University of Michigan Medical School, 102 Observatory Street, Ann Arbor, MI 48109-0724.

Copyright (C) 1991 Society for Neuroscience $0270-6474 / 91 / 111117-09 \$ 03.00 / 0$
}

rons and to $\mathrm{PCl} 2$ cells stimulates their elongation (Bray, 1984; Dennerll et al., 1989). This mirrors instances of tensile regulation of axonal elongation in vivo. Growth cones pull on neurites, stimulating their elongation (Lamoureux et al., 1989). In later stages of axonal development, migrating target cells pull on their attached axons, causing "towed" axonal growth (Weiss, 1941). Balice-Gordon and Lichtman (1990) report that a similar mechanical coupling between target cells and neurons is responsible for the growth of motor nerve terminals on mouse muscle fibers, thus integrating the size of the synapse with the size of the muscle fiber. Experimentally applied tension can also initiate new neurites from chick sensory cells (Bray, 1984). Conversely, sudden declines in neurite tension cause chick sensory neurites to develop tension actively and to retract (Dennerll et al., 1989), providing a potential mechanism for axonal retraction in vivo (Riley, 1981). Growth and retraction of neurites stimulated by supplying or withdrawing NGF to/from different regions of rat sympathetic neurons also appeared to be regulated by neurite tension (Campenot, 1985). Both axonal growth and retraction must involve assembly/disassembly of cytoskeletal elements. A complementary force interaction between compressed axonal microtubules supporting tensile axonal actin may regulate microtubule assembly in the axon by a thermodynamic mechanism, integrating microtubule assembly with growth cone advance (Buxbaum and Heidemann, 1988; Dennerll et al., 1988).

We report here further investigations of the relationship between axonal growth and mechanical tension. We wished to test the preliminary finding of Dennerll et al. (1989) that axonal elongation rate is linearly correlated with tension magnitudes. The procedure used for this experiment is similar to towed growth; for example, the active role of the growth cone is eliminated. New membrane is added at the growing tip in growthcone-mediated growth (Bray, 1970; Feldman et al., 1981; Pfenninger and Maylie-Pfenninger, 1981). Where is new membrane added when the growth cone is not actively involved in elongation? Finally, we wished to extend the work of Bray (1984) on neurite initiation by measuring the forces required to induce neurite initiation to determine if neurite initiation differs mechanically from elongation of extant neurites.

\section{Materials and Methods}

Materials. Polystyrene microspheres and Polybed 812 embedding resin were obtained from Polysciences, Inc. Phosphate-buffered saline and fetal bovine serum were purchased from Gibco. L-15 medium purchased from Sigma Chemical Co. was supplemented with $0.6 \%$ glucose, $2 \mathrm{~mm}$ L-glutamine, $100 \mathrm{U} / \mathrm{ml}$ penicillin, and $136 \mu \mathrm{g} / \mathrm{ml}$ streptomycin. Collagen IV, poly-L-lysine, trypsin, and polyethyleneimine were all purchased from Sigma Chemical Co. Laminin was obtained from Collaborative Research. A mouse monoclonal antibody against $\alpha$-tubulin was the kind gift of Dr. David Asai of Purdue University (Asai et al., 1982). 
Fluorescein-labeled goat anti-mouse IgG was purchased from Kirkegaard and Perry Lab., Inc.

Cell culture. Chick sensory neurons were isolated as described by Sinclair et al. (1988) from lumbosacral dorsal root ganglia of 10-12-dold chicken embryos and cultured in the supplemented L-15 medium described above containing $10 \%$ fetal calf serum and $100 \mathrm{ng} / \mathrm{ml} 7 \mathrm{~S}$ nerve growth factor isolated from mouse salivary glands (Varon et al., 1972). Cells were grown on untreated tissue culture dishes at a density low enough to render non-neuronal contamination inconsequential. Neurons werc culturcd for 16-24 hr prior to experimentation.

Neurite elongation and direct axial force and length measurement. The axial tension of neurites was measured with calibrated glass needles, and their length was determined as previously described (Dennerll et al., 1989). The bending moduli of the experimental needles were between 5.1 and $15.4 \mu \mathrm{dyn} / \mu \mathrm{m}$. A calibrated needle was attached to a neuron's growth cone, and the neurite was pulled in 30-60-min "steps" of constant force; that is, a tension magnitude was chosen, beginning at $50-100 \mu \mathrm{dyn}$, and this tension was held constant for $30-60 \mathrm{~min}$ by moving the micromanipulator to maintain the appropriate deflection of the calibrated needle. Subsequently, the same technique was used to apply 30-60-min periods of higher tension to the neurite, each level typically $25-50 \mu$ dyn higher than the previous value. The experiments were recorded on videotape at $24 \times$ time lapse and were subsequently analyzed for neurite length and tension as described previously (Dennerll et al., 1989).

In addition to an expected towed growth response (Bray, 1984), chick sensory neurons have a passive viscoelastic solid response to applied tension (Dennerll et al., 1989). In order to determine accurately the (inelastic) growth parameters from neurite length measurements, initial analyses subtracted the elastic stretching component of neurite length using a previously described mechanical model for passive viscoelastic behavior (Dennerll et al., 1989). Individual neurite values for the stiffness of the mechanical elements were obtained as described by Dennerll et al. (1989). The elastic response of a neurite to tension over time was calculated, and this value was subtracted from total neurite length to give a value for growth. These analyses showed that the rather small stretching increases for each tension step were complete after the first 10-15 min. Consequently, in later experiments growth rates could be calculated from length data omitting the first 15 min following tension increases.

Neurite initiation. Neurons without extant neurites were attached to calibrated experimental needles at the cell margins. The response of the cell to the application of various tension levels was recorded on videotape and analyzed for tension and neurite length as above.

Some experimentally initiated neurites were examined by immunofluorescence or by transmission electron microscopy for the presence of microtubules: Following initiation, neurites were subjected to tensions to allow continued elongation to various lengths. The distal ends of such neurites were then micromanipulated from the needle back onto the culture substrate. A diamond-tipped "objective" was used to mark the experimental neuron by circling the dish beneath. Immunofluorescent staining of microtubules was carried out by a method similar to that of Thompson et al. (1984): Medium was carefully removed, and the culture was permeabilized in $0.5 \%$ Triton X-100 in the microtubulestabilizing buffer described by Thompson et al. (1984), then fixed in formaldehyde solution in this same stabilization buffer, all at $37^{\circ} \mathrm{C}$, followed by extraction in methanol at $-20^{\circ} \mathrm{C}$. The neurites were then incubated with primary antibody to tubulin (kindly provided by Dr. David Asai), rinsed, then incubated with fluorescein-labeled secondary antibody. The prepared samples were viewed with a Nikon inverted microscope equipped for fluorescence observation. Electron microscopic observations of experimentally initiated neurites were made using standard methods previously described (Sinclair et al., 1988).

Neurite membrane addition and removal. Polystyrene microspheres $1.6 \mu \mathrm{m}$ in diameter were treated with $5 \%$ polyethyleneimine in water, then washed 5 times in distilled water and once in L-15 medium and stored in L- 15 medium at $0.8 \% \mathrm{w} / \mathrm{v}$. Ten microliters of the microsphere suspension were added to cell cultures containing 3-4 ml of culture medium. After incubating for $30-60 \mathrm{~min}$ at $37^{\circ} \mathrm{C}$ to allow the microspheres to attach to neurons, excess microspheres were removed by rinsing the culture with fresh medium. Calibrated needles were attached, as above, to the growth cones of neurites judged to be appropriately labeled with microspheres, and the neurites were pulled or slackened. The experimental process was videotaped, and the distances between cell body and microspheres were measured by the same procedure used to measure neurite length.

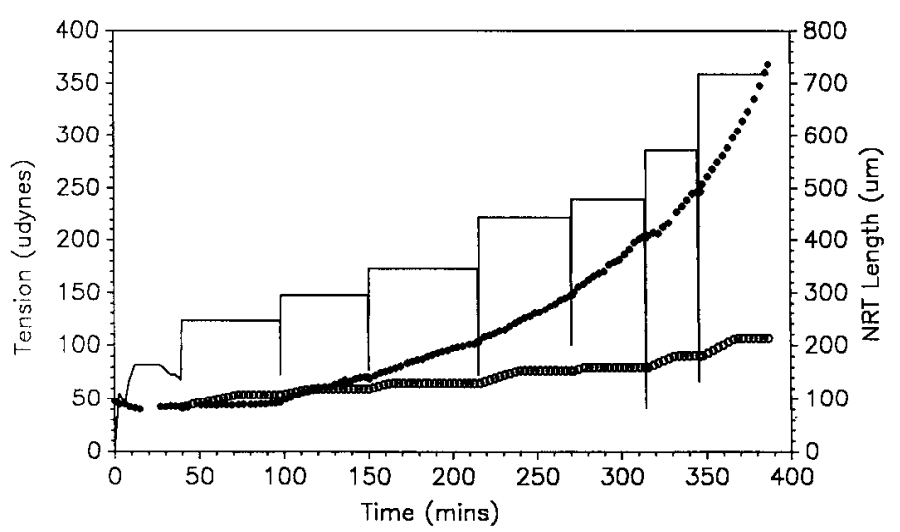

Figure 1. Neurite lenthening in response to increasing steps of tension. Chick sensory neurons were pulled from their distal ends by a calibrated glass needle. Bar graph, The deflection of the needle was stabilized by micromanipulation to exert various levels of force (left ordinate) on the neurite, which were maintained for 25-60 min before increasing the force to a new level. Upper, dotted line, Overall neurite length (right ordinate) from cell body to needle; lower, broad line, passive viscoelastic response of neurite predicted from neurite mechanical constants and the mechanical model for neurite response as described by Dennerll et al. (1989).

\section{Results}

\section{Control of neurite elongation by tension}

PC12 neurites subjected to experimentally applied tensions of less than $100 \mu$ dyn elongated as simple viscoelastic solids, showing no long-term extension. However, neurites showed plastic, long-term elongation, interpreted as growth, when subjected to tensions of $>100 \mu$ dyn. The long-term elongation rate above this threshold was proportional to the magnitude of the initially applied tension (Dennerll et al., 1989). These experiments, however, suffered from a technical limitation: Applied force declined as the neurite lengthened such that both neurite length and tension were changing at all times. We wished to confirm the findings of Dennerll et al. (1989) using a better-controlled method on authentic neurons. Fourteen chick sensory neurites were attached to calibratcd glass needles at their growth cones and subjected to increasing steps of tension. Each step was a period of constant force of 30-60-min duration, and steps differed from each other by 25-50 $\mu$ dyn. Figure 1 summarizes one such neurite-lengthening experiment. As for PC12, sensory neurites lengthened continuously above a threshold tension, here $43 \mu \mathrm{dyn}$. Also, neurite lengthening increased with increasing tension level. However, not all of this length increase was growth. Some portion of this neurite lengthening was elastic stretching because chick sensory neurites, like PC12 neurites, have a viscoelastic solid component to their extension behavior (Dennerll et al., 1989). The lower, broad line of Figure 1 plots the elastic response of the neurite predicted by a mechanical (springs and dashpot) model for the viscoelastic behavior of chick sensory neurons (Dennerll et al., 1989). As shown in Figure 1, this component of the behavior equilibrates a given tension by a given change in length (i.e., as an elastic solid) over a period of 10-15 min. Yet the neurite continues to elongate after this time, apparently at constant rate. We interpret the neurite elongation that follows this period of elastic equilibration as towed growth (Bray, 1984; Dennerll et al., 1989). Like Bray (1984), we found that this lengthening occurred with an apparent increase in volume of the neurite, that is, in the absence of neurite thinning expected 


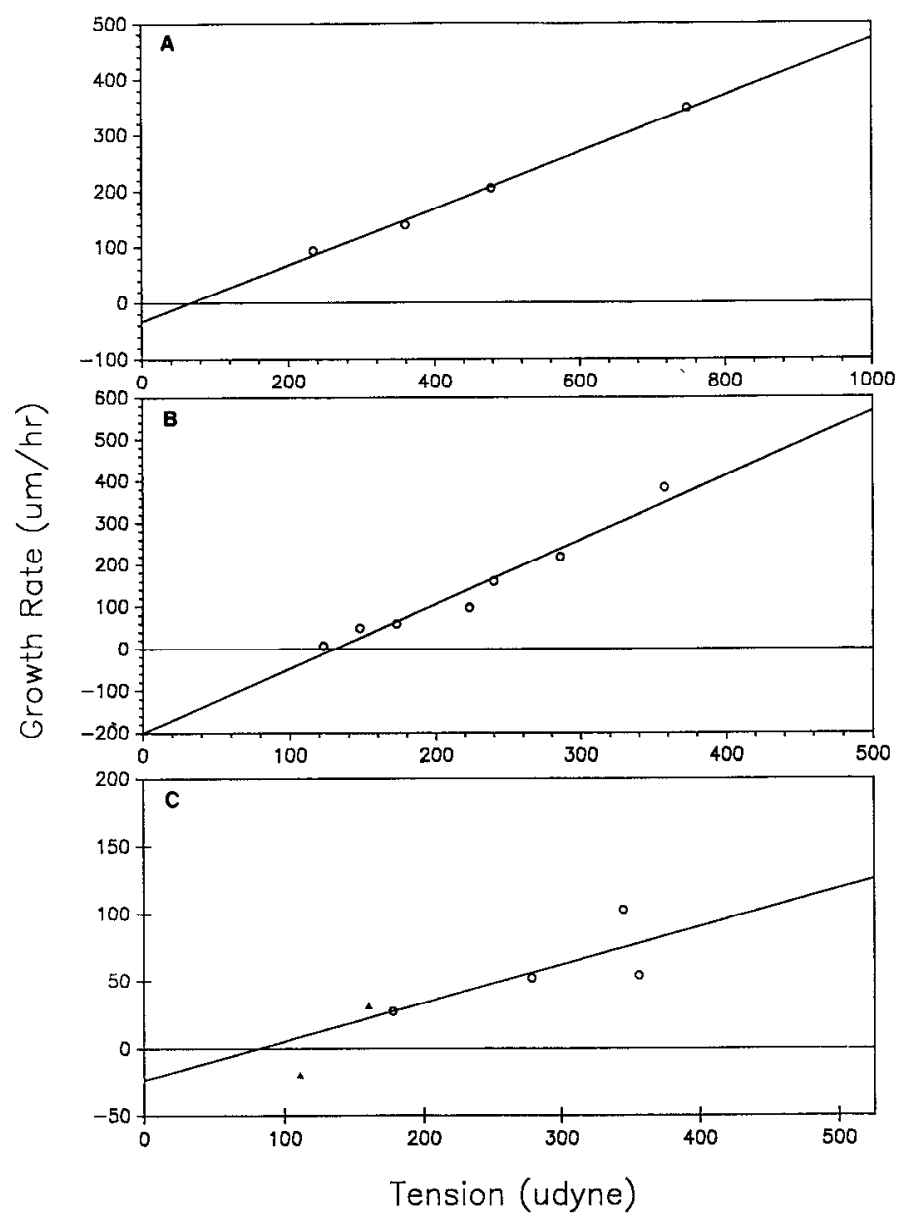

Figure 2. Growth rate of neurites (elongation rate corrected for elastic stretching) as a function of applied tension for 3 typical neurites. The slope of the line is the sensitivity of neurite growth to tension (see Fig. 3 ). The 0 growth intercept is the tension threshold for growth (see Fig. 4). The experiments shown in $A$ and $B$ consist of incremental steps of tension only, as in Figure 1. The experiment shown in $C$ includes 2 decremental steps of tension (triangles) among the incremental steps. Growth rate declined during decremental steps as expected.

of stretching except at the very highest elongation rates, and in the absence of cell body shrinkage (see Figs. 8, 9 for visual confirmation in a different context). We found, as shown in Figure 2, that this growth rate (i.e., corrected for elastic stretching) is proportional to tension magnitude above a tension threshold; that is, plots of growth rate versus tension for all 14 neurites showed a simple linear relation between tension above a threshold and growth rate. Correlation coefficients were between 0.83 and 0.99 and were greater than 0.9 for 10 of 14 neurites. As seen in Figure 2, this relationship holds even at quite high, nonphysiological rates of elongation, up to $400 \mu \mathrm{m} / \mathrm{hr}$. The application of uniformly increasing steps of force with accompanying neurite lengthening gave rise to the possibility that growth rate was proportional to neurite length, rather than tension. To check this, decremental tension steps were applicd among the incremental steps in a few experiments. In all cases, as shown in Figure $2 C$, growth rate declined with decreasing tension. This indicates that growth rate was a function of tension, not of neurite length.

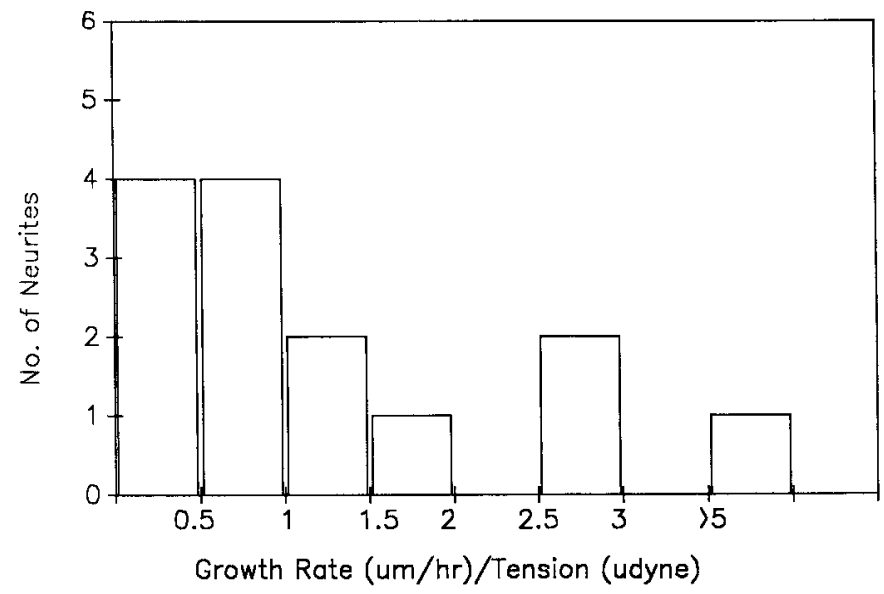

Figure 3. Frequency distribution of the tension sensitivity of neurite growth for 14 experimental neurites. Tension sensitivity is given as the growth rate per unit tension.

The relationship between elongation rate and tension, the slopes of the lines in Figure 2, reflects the sensitivity of neurite growth rate to tension, that is, the elongation rate per $\mu$ dyne of tension. Figure 3 is a frequency distribution of this sensitivity for the 14 neurites. Neurites' tension sensitivity varied; most neurites elongated between 0.2 and $2.0 \mu \mathrm{m} / \mathrm{hr} / \mu \mathrm{dyn}$. However, some neurites were more sensitive; one elongated $5.5 \mu \mathrm{m} / \mathrm{hr} /$ $\mu \mathrm{dyn}$. Indeed, the sensitivity of sensory neurites to tension was surprisingly high; that is, differences in force at our method's detection limit (approximately $5 \mu \mathrm{dyn}$ ) would cause a moderate difference in elongation rate in most neurites. We found no correlation between a neurite's initial length and its sensitivity to tension.

Dennerll et al. (1989) found that PC12 cells had a surprisingly reproducible tension threshold for growth of $100 \mu$ dyn. Figure 4 summarizes the tension threshold (the tension intercept at 0 growth rate as in Fig. 2) for all 14 neurites. Thresholds for chick sensory neurites are seen to vary between 35 and $560 \mu \mathrm{dyn}$, with the majority $(9 / 14)$ between 50 and $150 \mu \mathrm{dyn}$. This is similar to but more variable than the 100- $\mu$ dyn threshold for the clonal PC1 2 cells. An important confirmation of the tension threshold for growth was that 8 of 14 neurites that were subjected to initial tensions lower than their threshold ( 0 growth intercept from later analysis) either retracted or showed no growth. For example, a neurite whose 0 growth intercept was later found to be $140 \mu$ dyn retracted at $7 \mu \mathrm{m} / \mathrm{hr}$ when subjected to $115 \mu$ dyn of force. Two of these eight neurites also showed retraction when subjected to forces slightly above their threshold; for example, one neurite with an intercept of $120 \mu \mathrm{dyn}$ retracted at $138 \mu \mathrm{dyn}$. The remaining 6 neurites were not subjected to forces less than their threshold.

\section{Surface addition in towed growth}

It was of interest to determine where membrane addition occurs in experiments similar to those described above, which resemble towed growth, particularly in view of work by Campenot (1985), who found cvidence for "intercalatcd" growth and retraction, that is, mass addition and subtraction occurring in the middle of neurites. Microspheres treated with polyethyleneimine stick aggressively to the neuronal membrane and appear to be markers for membrane regions per se, similar to the carmine particles 


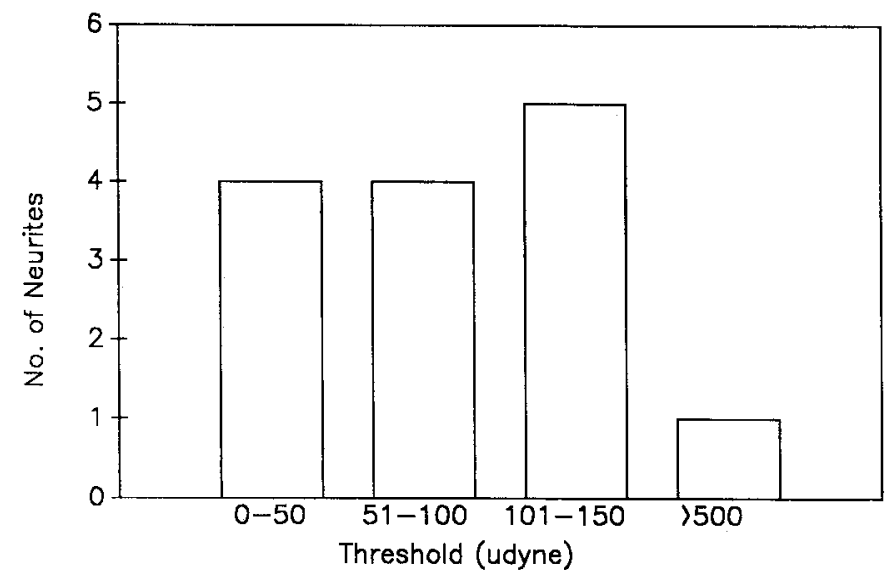

Figure 4. Frequency distribution of tension thresholds (tension value of 0 growth intercept from plots as in Fig. 2) for experimentally stimulated neurite growth from 14 experimental neurites.

used by Bray (1970). Labeled chick sensory neurites were elongated by pulling from the growth cone with glass needles, as above, and the videotape was analyzed for the changed distances of microspheres from the cell body. Figure 5 shows the results for 3 of the 7 neurites analyzed in this way. As shown in Figure $5 a$, microspheres remained essentially stationary on neurons that were not being pulled. In this experiment, there was some small drift in the position of the micromanipulator, allowing for a small amount of neurite retraction observable over the long run. Like Bray (1970), we found that microspheres were not moved by neuronal motility processes. However, microspheres did oscillate slightly when observed at time-lapse speed $(24 \times)$, as described by Bray (1970) for carmine particles. In pulled neurites, as shown in Figure 5, $b$ and $c$, the distance between microspheres and between most microspheres and the cell body increased. However, different regions of neurites clearly varied in the extent of change. For example, in Figure $5 b$, a substantial change in the distance of the microspheres symbolized by squares (arrowhead) contrasts with the nearly stable position of the microsphere nearest the cell body. There was also some tendency for the greatest separation to occur in the distal half of neurites, as shown in Figure 5, $b$ and $c$.

A similar analysis for marking membrane addition during neurite retraction is shown in Figures 6 and 7. We previously found that slackening neurites initiated active contraction and tension generation (Dennerll et al., 1989). Six neurites tethered at their growth cone were slackened in a series of short steps to cause retraction, as shown in Figure 6. An effort was made to hold the neurite close to 0 tension so that it was under neither tension nor compression. As shown in Figure 6, this gave rise to small, local sinusoids, but the entire neurite was not permitted to slacken into a sinusoid, as occurs upon axotomy (Baas et al., 1987). The videotape of such experiments was analyzed for the decrease in the distance of microspheres from the cell body, data shown in Figure 7. Figure $7 a$ shows the data from a control neurite that was not slackened and did not retract; microspheres maintained their positions relative to each other and to the cell body. In slackened neurites, the distances between microspheres decrcascd all along the neurite but, as for elongation, to a highly variable extent. For example, the neurite shown in Figure $7 b$ lost surface primarily from the most distal regions. Analysis of retraction was complicated by the fact that, as the neurite re-

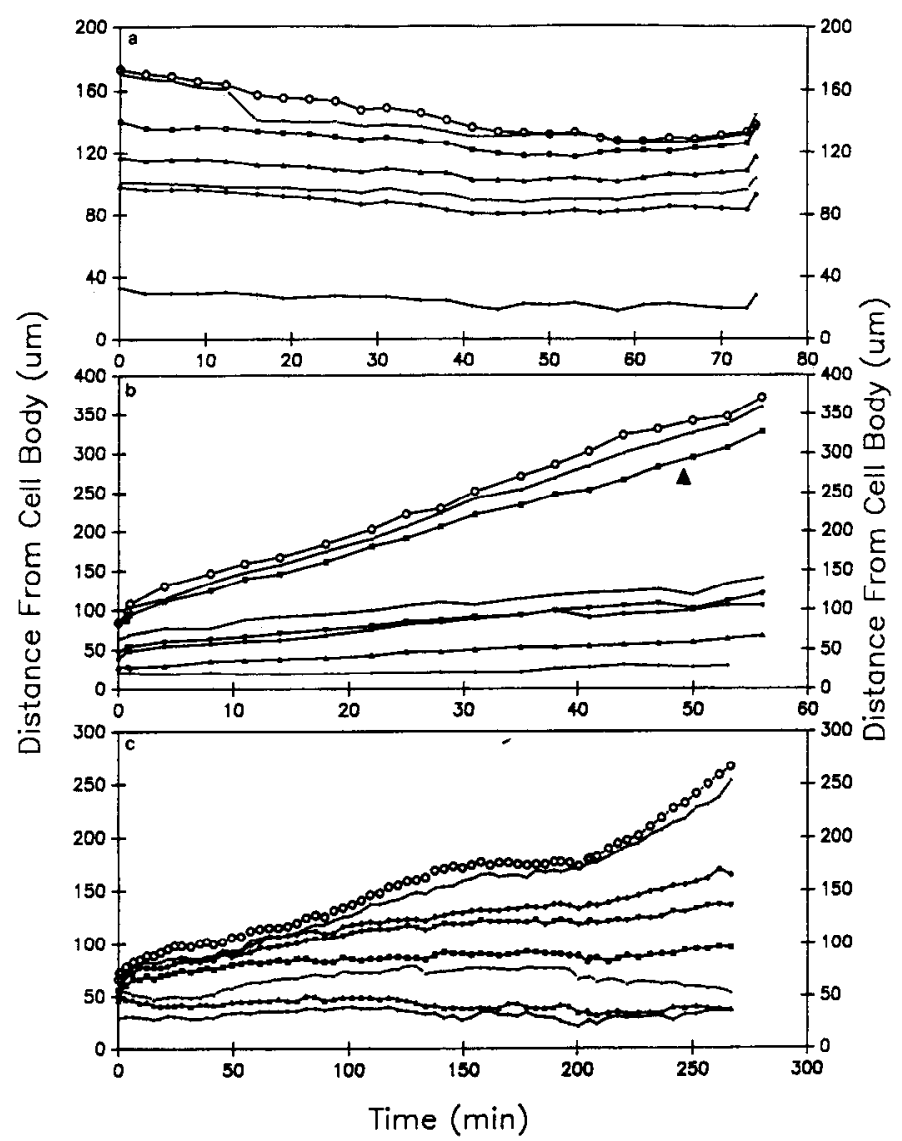

Figure 5. Surface movements of 3 neurites subjected to tension-induced neurite elongation. Neurite surfaces were labeled with polyethyleneimine-treated vinyl microspheres. The position of these microspheres relative to the cell body was recorded as the neurite was lengthened by pulling with a glass needle. The open circles represent the position of the growth cones. All other symbols represent particular microspheres, with their time course of position change given as a connecting solid line. a, Control neurite tethered onto a glass needle but not pulled. Some drift in the position of the micromanipulator allowed some neurite retraction during the course of the experiment. $b$, A neurite that showed particularly variable surface movement. As seen here, most of the surface movement occurred between the second microspheres behind the growth cone (arrowhead) and the microsphere behind it. As seen at $t=0$, these microspheres were originally located in the distal third of the neurite. $c$, A neurite that showed more evenly distributed surface movements as elongation proceeded.

tracted, some microspheres came too close together to resolve. This is apparent in Figure $7 b$, in which some lines representing microsphere position terminate at various time points. In contrast, the neurite shown in Figure $7 \mathrm{c}$ lost surface proportionately throughout its length.

\section{Neurite initiation}

Bray (1984) showed that neurites could be initiated de novo by experimentally applied tension. We wished to confirm and extend this result on neurons without extant neurites. Before experimental intervention, some experimental neurons were completely devoid of extensions from the rounded cell margins, while others (Fig. 8a) had motile lamellipodial extensions extending from the cell margins as described by Collins (1978). Calibrated glass needles were applied tangent to the margin of cells in random locations. No differences were noted among 

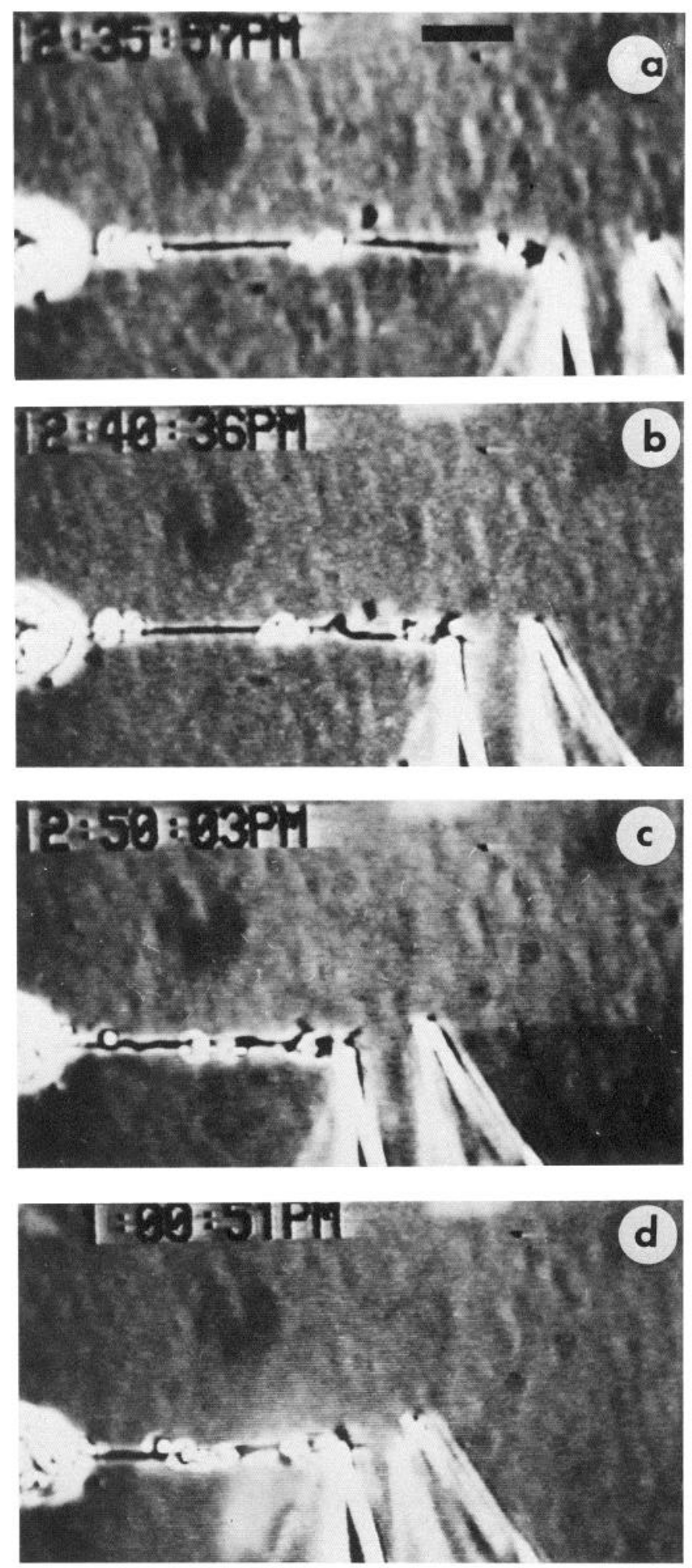

Figure 6. Phase images of neurite retraction, with treated microspheres marking the neurite surface, as photographed from the videotape of the experiment. $a$, Neurite decorated with microspheres immediately prior to the initial slackening. $b$, Five minutes later, a small sinusoid typically seen during these experiments can be seen distal to a microsphere group. $c$, Ten minutes later, the neurite has again been slackened, and small sinusoids can be seen. $d$, Ten minutes later, the sinusoids seen in $c$ have been resorbed. The neurite retracted $50 \mu \mathrm{m}$ during the $25 \mathrm{~min}$ of this sequence. Scale bar, $20 \mu \mathrm{m}$ for $a-d$.

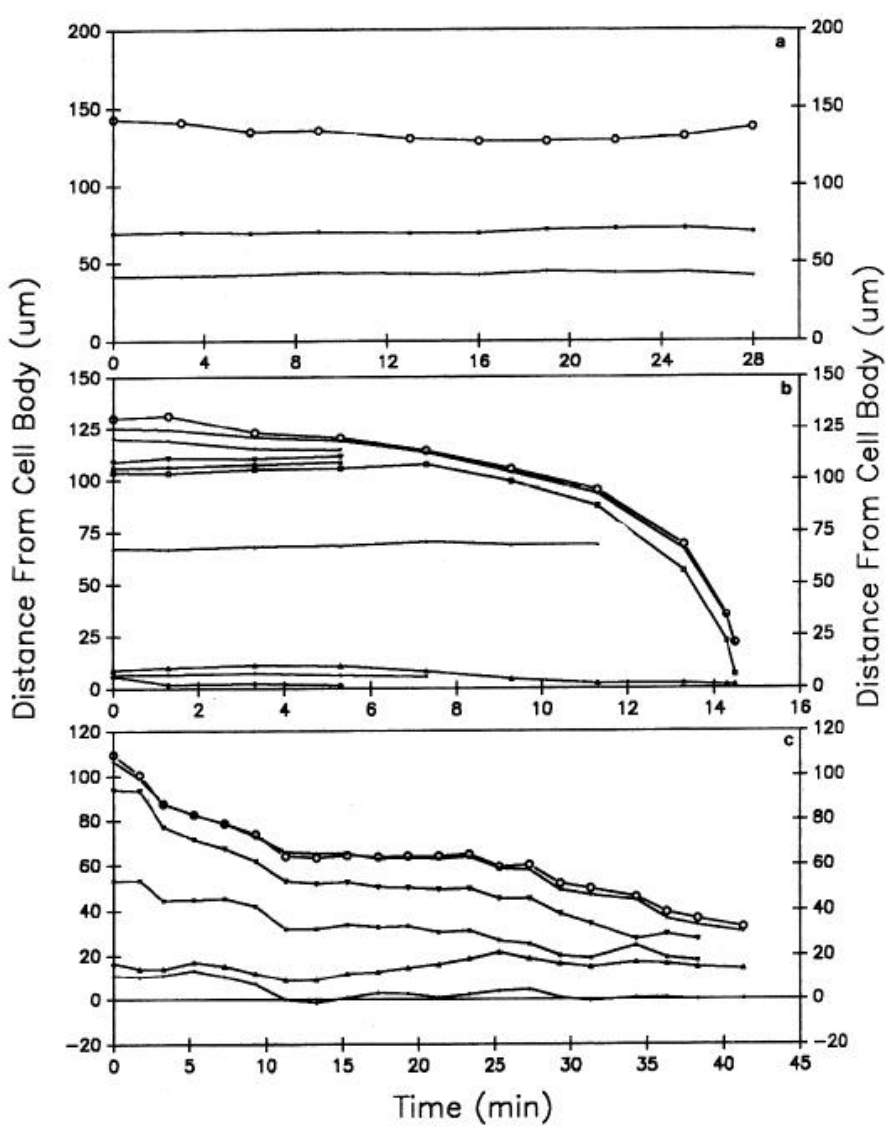

Figure 7. Surface movements of 3 neurites allowed to retract in response to neurite slackening. Surface movements were marked with microspheres as for Figure 6. Symbols are as in Figure 5. a, Control neurite tethered to glass needle but not slackened. $b$ and $c$, Position of microspheres and growth cones of neurites retracting in response to slackening. In some experiments, microspheres converged due to neurite shortening such that they could no longer be resolved as separate. This is reflected in the termination of several lines at various times in Figure $7 B$.

various regions of the margin for the capacity to initiate neurites, with the single exception of margins near asymmetrically located nuclei; that is, cell margins overlying a thin layer of cytoplasm between the plasma membrane and the nuclear membrane could not be induced to form neurites. Applied tensions of $60-1000$ $\mu$ dyn caused a cell process to form and elongate (Fig. $8 b$ ) in $80 \%$ of the cells to which tension was applied. In the remaining $20 \%$ of cells, applied tensions only caused the cell body to elongate but failed to cause process formation, even tensions $>1000$ $\mu$ dyn. As shown in Figures 8 and 9 , the elongation of initiated neurites occurred without obvious thinning of the lengthening neurite, nor was a decline in cell body volume apparent.

In total, we initiated neurites of varying lengths from 41 neurons and obtained some force measurements from 35 of these. We generally found no lag time for neurite formation after force application; 33 of 41 neurons responded immediately with changes of some type. In some of these cases, however, the cell elongated before an obvious process formed. In other cases, an obvious process formed immediately. Process formation generally occurred at the cell margin attached to the needle. In 7 cases, the process formed at the cell margin opposite the needle (Fig. $9 a-c)$. That is, micromanipulation pulled the cell body, and the process remained attached to the dish at its distal end, sug- 

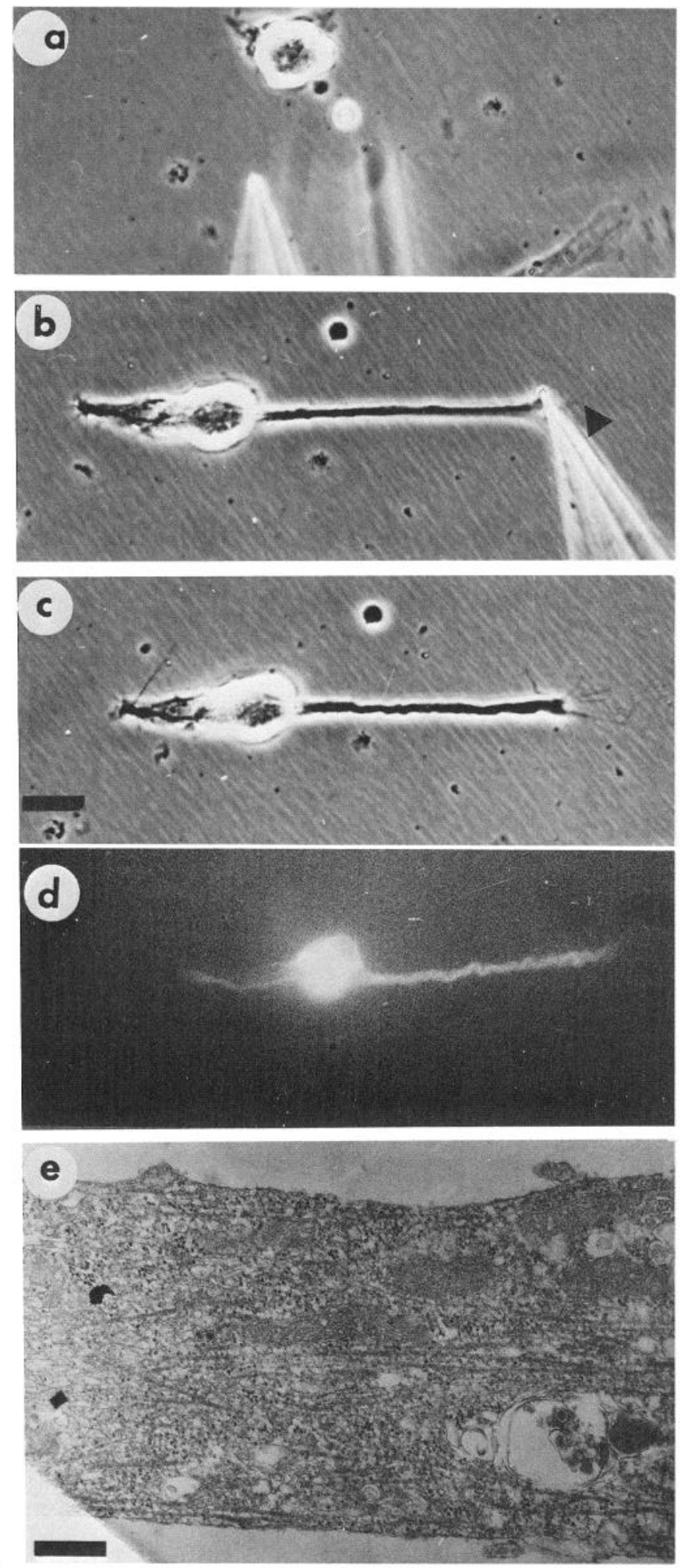

Figure 8. De novo initiation of neurites from chick sensory neurons by applied tension. $a$, Neuron prior to needle attachment. $b$, Same cell as in previous frame after $96 \mathrm{~min}$ of experimentally applied tension. In this cell, neurite initiation occurred both at the site of needle attachment to the cell margin and at the opposite cell margin. The arrowhead points to filopodia on the distal end of the neurite attached to the needle. Note also the growth-cone-like appearance of the distal end opposite the site of needle attachment. $c$, Eight minutes later, the distal end of the neurite formerly attached to the needle has been manipulated onto the culture dish. The growth-cone-like appearance of this end is apparent. $d$, The gesting that tension per se, not the needle or its surface treatment, stimulated the initiation process. As for elongation of extant neurites, there was evidence that neurite initiation required tension above some threshold; that is, in 10 neurons we found that initial applied forces were insufficient to initiate neurites, but that subsequent higher tensions were immediately successful. For example, 1 neuron failed to respond to tensions of 73 and $98 \mu$ dyn applied for 5 min each, but rapidly produced a neurite at $123 \mu \mathrm{dyn}$. However, we have no information about the threshold of most cells because initiation is a singular occurrence (one cannot "go back" and try a lower tension if the initial tension is successful), not a continuous variable (one also cannot extrapolate a graph back to a 0 intercept). The forces at which neurites were successfully initiated are as follows: The majority $(21 / 35)$ required less than $200 \mu \mathrm{dyn}$; in 5 cases forces $<100$ $\mu$ dyn initiated neurite formation. Four neurons initiated neurites in response to forces between 200 and $300 \mu \mathrm{dyn}, 7$ neurons formed processes between 300 and $600 \mu \mathrm{dyn}$, and 3 neurons initiated neurites in response to forces $>800 \mu \mathrm{dyn}$. We do not understand the basis of this wide variability in tension required to initiate neurites. Cell body size, for example, was not a factor. The only systematic difference was that more force was generally required for those neurites "towed" by the cell body, as in Figure 9, than for those neurites towed by their distal end, as in Figure 8. Although the variability is poorly understood, sensory neurons are a heterogeneous group of cells, so the differences are not entirely surprising.

In many cases, initiation appeared to consist of 2 phases. Initially, a "bump" or "nubbin" formed, and this was easily drawn out from the cell margin for a period of some 10-20 min. During this period, too high a force frequently caused the process to break or caused a loss of attachment to the needle. Subsequent elongation from the nubbin was somewhat slower and frequently involved a higher force, though generally still less than $200 \mu \mathrm{dyn}$. Unlike elongation from extant neurites, elongation of neurites initiated de novo was not linearly related to force. Rather, neurites appeared to elongate at a particular rate despite increases in applied tension (Fig. 10). Nevertheless, neurites initiated de novo developed microtubules and growth cones, 2 important characteristics of "normal" neurites. Motile filopodia were noted on 7 neurites while still attached to the needle (Fig. $8 b$ ). As shown in Figure $8 c$, if the distal ends were manipulated off the needle back onto the dish, these ends strongly resembled growth cones. As shown in Figure 9, growth cones also formed on all 7 neurons that were towed by the cell body rather than by the neurite. This indicates that the presence of the needle was not responsible for growth cone formation. Most importantly, the growth cones formed by tension engaged in motile activity such as filopodial extension/retraction and could advance along the dish, causing neurite elongation, as shown clearly in Figure 9, $c$ and $d$. We did not attempt to assess the existence of growth cones on the distal ends of neurites that did not show filopodia while still attached to the needle because of competing experimental demands on initiated neurites, some for electron mi-

same cell as in $c$ fixed and processed for immunofluorescence with a monoclonal antibody against $\alpha$-tubulin (see Materials and Methods). $e$, Transmission electron micrograph of a neurite initiated de novo by experimentally applied tension (not the same cell as shown in $a-d$ ). Microtubules are readily apparent. Scale bars: $a-d, 20 \mu \mathrm{m} ; e, 0.5 \mu \mathrm{m}$. 

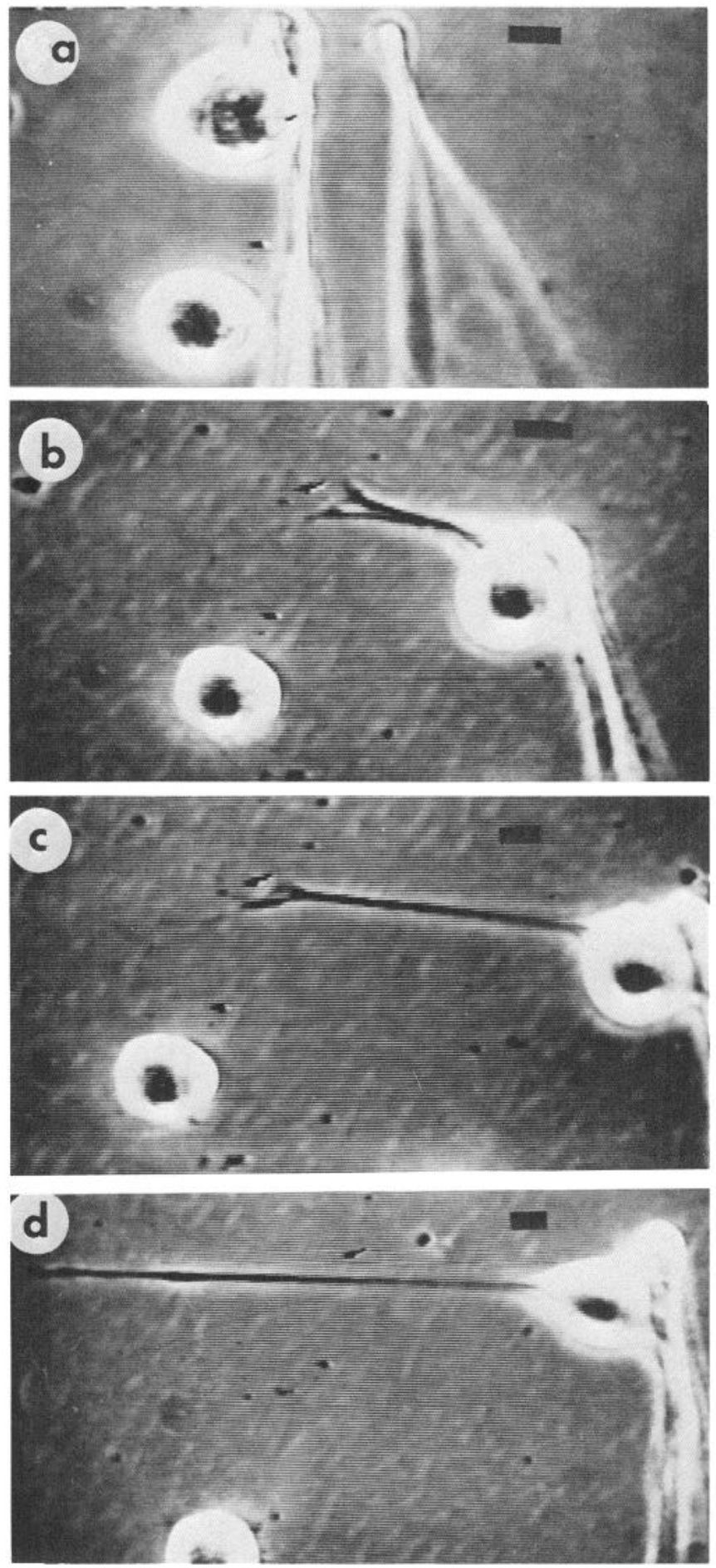

Figure 9. De novo initiation of neurites from chick sensory neurons by tension applied to the cell body. These micrographs were taken from the videotape of the experiment. $a$, Prior to the beginning of tension application. A neuron with no outgrowths was attached to a glass needle. $b$, A neurite formed on the margin of the cell opposite the pulling needle. This micrograph was taken $22 \mathrm{~min}$ after tension was first applied to the cell margin. Note the growth-cone-like appearance of the distal end and the attachment point of this end relative to the cell below. $c$, Fifteen minutes later, the neurite elongated by towing of the cell body, i.e., without a change in the position of distal end of the neurite. This micrograph reflects the maximum extent of towed growth for this neurite; i.e., no additional movements of the micromanipulator were imposed after this time. $d$, Thirty-three minutes later, additional neurite elongation was caused during this period by the advance of the growth

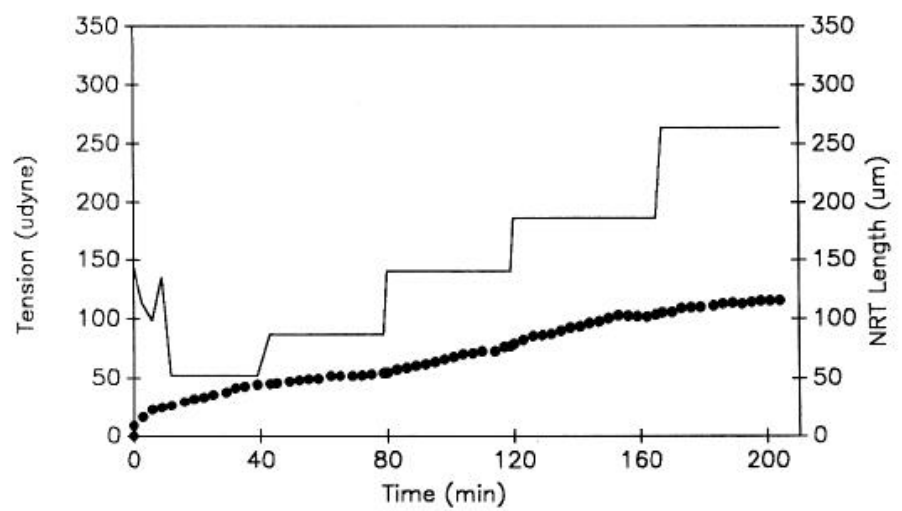

Figure 10. The elongation of a neurite initiated by experimentally applied tension in response to a step function of increasing tension. The solid line shows the tension magnitudes applied to a neuron as 30-40min periods of constant force. The solid circles show the net length of the neurite. In contrast to self-initiated neurites (Fig. 1), experimentally initiated neurites did not show a dependence of elongation rate with tension magnitude.

croscopy, some for cytomechanical analysis of long duration, and so on. In addition to functional growth cones, experimentally initiated neurites were found to contain microtubules. We examined 10 cells for neurite microtubule content by either immunofluorescence or transmission electron microscopy. All 8 of the initiated neurites longer than $10 \mu \mathrm{m}$ were found to contain microtubules, as shown in Figure $8, d$ and $e$. As shown in Figure $8 d$, the tubulin-immunofluorescent image in initiated neurites showed a bundle of microtubules in which individual polymers could not be resolved. This is typical of neurons (e.g., Goslin et al., 1989; Baas and Black, 1990; Lim et al., 1990) and of cells experimentally induced to express $\tau$, a major microtubule-associated protein of axons (Kanai et al., 1989). Of 2 neurites less than $10 \mu \mathrm{m}$ long, one was found to contain microtubules by immunofluorescence, and the other was found to be devoid of microtubules by electron microscopy.

\section{Discussion}

In towed growth, an axon elongates after attachment to its target as a result of tension exerted on the axon by target movements (Weiss, 1941). The experimental technique used here, attaching a glass needle to the distal end of a neurite and pulling, is an in vitro analog of this growth phase. Recent reports suggest an important role for towed growth in the extension of retinal ganglion cell dendrites of fish (Hitchcock, 1987) and cats (Mastronarde et al., 1984), in neuronal pathway formation within the visual system of Drosophila (Steller et al., 1987), and in size matching of pre- and postsynaptic elements of the neuromuscular junction of rats (Balice-Gordon and Lichtman, 1990). Despite this and considerable older evidence concerning towed growth, studies of tension-induced axonal growth have been very limited; our work can be regarded as an extension of that of Bray (1984), who fixed the elongation rate of neurites by towing with a specially designed towing motor. This allowed investigation of towed growth at slow rates, but provided no

cone, as seen by the change in the position of the neurite growth cone relative to the cell below. Scale bars, $10 \mu \mathrm{m}$ in $a-d$. 
information about forces. We, in contrast, fixed the force and observed the elongation. This allowed an analysis of the relationship between force and elongation rate. We found that chick sensory neurons are surprisingly sensitive to tension. Some neurites have a growth rate $(\mu \mathrm{m} / \mathrm{hr})$ to tension ( $\mu \mathrm{dyn})$ ratio of $5: 1$ (Fig. 3). An aspect of this sensitivity is that the elongation rates we observed were often higher than the most rapid growth-conemediated elongation rates reported for these neurons in culture (approximately $100 \mu \mathrm{m} / \mathrm{hr}$; Bray, 1984). However, we found no difference in the growth/tension relationship at elongation rates above and bclow this benchmark (c.g., Fig. 2B).

We found that the growth rate of chick sensory neurites is proportional to tension above a threshold. This result confirms our earlier interpretation of tension-stimulated growth in PC12 cells and, from a cytomechanical perspective, confirms a fundamental similarity between axonal growth and Bingham fluid behavior, that is, a linear relation between rate of length change and force above a threshold. The linear relationship between tension and growth rate is attractive heuristically in that it accounts both for axons accommodating small forces without growth and for large-sale tissue expansion without progressive changes in the steady-state tension on axons. If growth amount were proportional to tension, for example, very long axons would be under much greater tension than short axons and would bear increasingly higher tension as the organism grew. We observed that tensions below a threshold produced a 0 growth rate. Thus, axons can accommodate tissue growth precisely if the level of tension on the axon increases with the rate of tissue expansion, an intuitively reasonable situation. Tension regulation of towed growth may then resemble typical physiological control mechanisms characterized by "set points." In this case, there is an axonal tension set point: Axons bear some tension, as shown for cultured neurons (Bray, 1979; Dennerll et al., 1989). Tissue growth exerts additional tension on associated axons, stimulating their elongation. This axonal elongation dissipates the tension because the axon is adding mass to accommodate the increase in length rather than stretching elastically (imagine a spring that added gyres when pulled). As tissue expansion slows to a halt, tension on the axon declines with the addition of mass until it declines below threshold, where it remains unless the tissue again expands. Thus, moderate steady-state values for tensions on axons are maintained.

New surface is added at the growth cone in growth-conemediated axonal elongation (Bray, 1970; Feldman et al., 1981; Pfenninger and Maylie-Pfenninger, 1981). Microtubules are also added at the distal end in growth-cone-mediated elongation (Bamburg et al., 1986; Lim et al., 1990). In contrast, the assumption in towed growth is that mass addition is interstitial (Hitchcock and Easter, 1986), a possibility that is supported by experimental results of Campenot (1985). We labeled the surface of towed neurites with polycationic microspheres, similar to Bray's (1970) use of carmine particles, to determine whether new surface was added interstitially and to observe the pattern, if any, to the addition. The polyethyleneimine-treated microspheres did not translocate significantly relative to the cell body in the absence of pulling. Most importantly, the sum of the increased distances between microspheres during towed growth equaled the increased length of the neurite. These observations provide strong evidence that the movement of microspheres relative to the cell body during towed growth represents regions of new surface addition. As expected, we found that new surface was added interstitially along the entire length of the neurite
(Fig. 5). However, new surface addition did not occur uniformly throughout the neurite. There was some tendency for the new surface to be added preferentially at the distal half of neurites, as shown in Figure $5, b$ and $c$. Also, as shown in Figure $5 b$, new surface tended to be added in particular regions of a given neurite, while other regions added little or no new surface; that is, towed growth was similar to growth-cone-mediated elongation in that some regions of the neurite were favored for membrane insertion relative to other regions. New membrane arises from the fusion of membranous vesicles with the axolemma following the synthesis of the vesicles in the cell soma and rapid transport down the axon (for review, see Pfenninger, 1987). The nature of the signal that specifies sites for vesicle off-loading from the transport system and/or for vesicle fusion is completely unknown. However, our results complement previous findings on growth-cone-mediated growth by providing evidence for regionalization of axolemmal growth during towed growth. Also, the differing sites of addition in growth-cone-mediated and towed elongation imply that this regionalization is sensitive to the mode of growth.

Initiation of axons/dendrites appears to be a process distinct from elongation. Motile, "amoeboid" activity is initially characteristic of most, if not all, of the cell margin of cultured neurons (Collins, 1978; Wessells, 1982; Dotti et al., 1988). Motility is then restricted to particular regions, and ultrastructural observation of such incipient outgrowths, both in culture and in situ, shows cytoskeletal elements concentrated at these sites (Lyser, 1964, 1968; Tennyson, 1965; Stevens et al., 1988). However, a cause and effect relationship between spatial restriction of motility and the concentration of cytoskeletal elements remains elusive: No change in cell body ultrastructure predictive of the site of axonal initiation has been noted. Our evidence that mechanical force can both initiate neurites and regulate microtubule assembly suggests the possibility that tension may be a link between motile activity and cytoskeletal assembly in process outgrowth. Mechanical tension as a regulator of axonal microtubule assembly has been discussed previously (Buxbaum and Heidemann, 1988; Mitchison and Kirschner, 1988). The apparently normal density of microtubules within neurites initiated and elongated by experimentally applied tension (Fig. 8e) provides strong additional evidence that mechanical force can regulate axonal microtubule assembly both spatially and temporally. More unexpected was the finding that tension stimulated the formation of functional growth cones at the ends of tension-induced neurites. In neurons with an appropriately differentiated state, tension appears to be sufficient to regulate spatially and initiate the formation of 2 crucial structures characteristic of sprouting neurons: an axonal microtubule array and a growth cone. The forces required to initiate neurites, less than $200 \mu \mathrm{dyn}$ in most cases, were in the same range as those for elongation of extant neurites. It is somewhat surprising that initiation required no greater tension than did elongation; the initiation and spatial organization of cytoskeletal assembly might be expected to require an additional energy input. However, the force magnitudes required for initiation and elongation were entirely consistent with the tensions (generally above $200 \mu$ dyn, up to $500 \mu$ dyn) these neurons exert on themselves by their pulling growth cone (Lamoureux et al., 1989) and by active neurite retraction (Dennerll et al., 1989). We speculate that the restriction of motility observed in "normal" neurite initiation in culture reflects the first motile region to exert more tension than the threshold for neurite initiation. Possibly, this effective 
pulling growth conc then inhibits motility elsewhere by mechanical effects on the cytoskeleton as described by Kolega (1986) for inhibition of fish epidermal cell motility by experimentally applied tension. The tension exerted by the newly formed growth cone may induce neurites by concentrating cytoskeletal elements or may stimulate cytoskeletal assembly in the region (Buxbaum and Heidemann, 1988).

The available evidence on mechanical stimulation of axonal elongation raises the possibility that tension serves as a general regulator, acting as a kind of "second messenger" (Mitchison and Kirschner, 1988). It will be of interest to test whether the effects of various extrinsic regulators of axonal elongation such as NGF (Campenot, 1985), $\mathrm{Ca}^{2+}$ levels (Kater et al., 1988), and properties of the growth substrate (Letourneau, 1982) act through this "second messenger" to stimulate elongation.

\section{References}

Asai DJ, Brokaw CJ, Harmon RC, Wilson L (1982) Monoclonal antibodies to tubulin and their effects on the movement of reactivated sea urchin sperm. Cell Motil [Suppl] 1:175-180.

Baas PW, White LA, Heidemann SR (1987) Microtubule polarity reversal accompanies regrowth of amputated neurites. Proc Natl Acad Sci USA 84:5272-5276.

Baas PW, Black MM (1990) Individual microtubules in the axon consist of domains that differ in both composition and stability. $\mathbf{J}$ Cell Biol 111:495-509.

Balice-Gordon RJ, Lichtman JW (1990) In vivo visualization of the growth of pre- and postsynaptic elements of neuromuscular junctions in the mouse. J Neurosci 10:894-908.

Bamburg JR, Bray D, Chapman K (1986) Assembly of microtubules at the tips of growing axons. Nature 321:788-800.

Bray D (1970) Surface movements during the growth of single explanted neurons. Proc Natl Acad Sci USA 65:905-910.

Bray D (1979) Mechanical tension produced by nerve cells in tissue culture. J Cell Sci 37:391-410.

Bray D (1984) Axonal growth in response to experimentally applied tension. Dev Biol 102:379-389.

Buxbaum RE, Heidemann SR (1988) A thermodynamic model for force integration and microtubulc asscmbly during axonal elongation. J Theor Biol 134:379-390.

Campenot RB (1985) The regulation of nerve fiber length by intercalated elongation and retraction. Dev Brain Res 20:149-154.

Collins F (1978) Induction of neurite outgrowth by a conditionedmedium factor bound to the culture substratum. Proc Natl Acad Sci USA 75:5210-5213.

Dennerll TJ, Joshi HC, Steel VL, Buxbaum RE, Heidemann SR (1988) Tension and compression in the cytoskeleton: II. Quantitative measurements. J Cell Biol 107:665-674.

Dennerll TJ, Lamoureux P, Buxbaum RE, Heidemann SR (1989) The cytomechanics of axonal elongation and retraction. J Cell Biol 109: 3073-3083.

Dotti CG, Sullivan CA, Banker GA, Banker GA (1988) The establishment of polarity by hippocampal neurons in culturc. J Ncurosei 8:1454-1468.

Feldman EL, Axelrod D, Schwartz M, Heacock AM, Agranoff BW (1981) Studies on the localization of newly added membrane in growing neurites. J Neurobiol 12:591-598.

Goslin K, Birgbauer E, Banker G, Solomon F (1989) The role of cytoskeleton in organizing growth cones: a microfilament-associated growth cone component depends upon microtubules for its localization. J Cell Biol 109:1621-1631.

Heidemann SR, Buxbaum RE (1990) Tension as a regulator and integrator of axonal growth. Cell Motil Cytoskel 17:6-10.
Hitchcock PF (1987) Constant dendritic coverage by ganglion cells with growth of the goldfish's retina. Vision Res 27:17-22.

Hitchcock PF, Easter SS (1986) Retinal ganglion cells in goldfish: a qualitative classification into four morphological subtypes and a quantitative study of one of them. J Neurosci 6:1037-1050.

Kanai Y, Takemura R, Oshima A, Mori H, Ihara Y, Yanagisawa M, Masaki T, Hirokawa N (1989) Expression of multiple tau isoforms and microtubule bundle formation in fibroblasts transfected with a single tau cDNA. J Cell Biol 109:1173-1184.

Kater SB, Mattson MP, Cohan C, Connor J (1988) Calcium regulation of the neuronal growth cone. Trends Neurosci 11:315-321.

Kolega J (1986) Effects of mechanical tension on protrusive activity and microfilament and intermediate filament organization in an epidermal epithelium in culture. J Cell Biol 102:1400-1411.

Lamoureux P, Buxbaum RE, Heidemann SR (1989) Direct evidence that growth cones pull. Nature 340:159-162.

Letourneau PC (1982) Nerve fiber growth and its regulation by exIrinsic factors. In: Neuronal development (Spitzer NC, ed), pp 213254. New York: Plenum.

Lim S-S, Edson KJ, Letourneau PC, Borisy GG (1990) A test of microtubule translocation during neurite elongation. J Cell Biol 111: 123-130.

Lyser KM (1964) Early differentiation of motor neuroblasts in the chick embryo as studied by electron microscopy. Dev Biol 10:433466.

Iyser KM (1968) Early differentiation of motor neuroblasts in the chick embryo as studied by electron microscopy. II. Microtubules and neurofilaments. Dev Biol 17:117-142.

Mastronarde DN, Thibeault MA, Dubin MW (1984) Non-uniform postnatal growth of the cat retina. J Comp Neurol 228:598-608.

Mitchison T, Kirschner M (1988) Cytoskeletal dynamics and nerve growth. Neuron 1:761-772.

Pfenninger KH (1987) Plasmalemmal properties of the sprouting neuron. Curr Top Dev Biol 21:185-206.

Pfenninger KH, Maylie-Pfenninger M-F (1981) Lectin labeling of sprouting neurons. I. Regional distribution of surface glycoconjugates. J Cell Biol 89:536-546.

Riley DA (1981) Ultrastructural evidence for axon retraction during spontaneous elimination of polyneural innervation of the rat soleus muscle. J Neurocytol 10:425-440.

Sinclair GI, Baas PW, Heidemann SR (1988) Role of microtubules in the cytoplasmic compartmentation of neurons. II. Endocytosis in the growth cone and neurite shaft. Brain Res 450:60-68.

Steller H, Fischbach K-F, Rubin GM (1987) Disconnected: a locus required for neuronal pathway formation in the visual system of Drosophila. Cell 50:1139-1153.

Stevens JK, Trogadis J, Jacobs JR (1988) Development and control of axial neurite form: a serial electron microscopic analysis. In: Intrinsic determinants of neuronal form and function (Lasek RJ, Black MM, eds), pp 115-146. New York: Liss.

Tennyson VM (1965) Electronmicroscopic study of the developing neuroblast of the dorsal root ganglion of the rabbit embryo. J Comp Neurol 124:267-318.

Thompson WC, Asai DJ, Carney DH (1984) Heterogeneity among microtubules of the cytoplasmic microtubule complex detected by a monoclonal antibody to alpha tubulin. J Cell Biol 98:1017-1025.

Varon S, Nomura J, Perez-Polo J, Shooter EM (1972) The isolation and assay of nerve growth factor proteins. In: Methods of neurochemistry, Vol 3 (Fried R, ed), pp 203-229. New York: Dekker.

Weiss P (1941) Nerve pattern: the mechanics of nerve growth. Growth [Suppl 3d Growth Symp] 5:163-203.

Wessells NK (1982) Axon elongation: a special case of cell locomotion. In: Cell behavior (Bellairs R, Curtis A, Dunn G, eds), pp 225-246. Cambridge: Cambridge UP. 